\title{
Dynamic Characteristics of The Spool-Type Constant-Flow Valves*
}

\author{
Yuan $\mathrm{KANG}^{* *}$, Sheng-Yen HU**, Sheng-Chuan CHEN** and Yeon-Pun CHANG** \\ ${ }^{* *}$ Department of Mechanical Engineering \\ Chung Yuan Christian University, Chung-Li 320, Taiwan, R.O.C. \\ E-mail: yk@cycu.edu.tw
}

\begin{abstract}
Constant flow valves have been presented in industrial applications or academic studies, which compensate recess pressures of a hydrostatic bearing to resist load fluctuating. The flow rate of a constant-flow valve can be constant in spite of the pressure changing in a recess. However the design parameters of this type valve must be specified. This paper analyzes the dynamic responses of the spool-type constant-flow valve that is designed as a spool-type restrictor but with matched preloading spring and supply pressure. In this study the static analysis presents the specific relationships among design parameters for constant flow rate and the dynamic analyses give the variations around the constant flow rate as the working pressure fluctuates.
\end{abstract}

Key words: Constant-Flow Valve (CFV), Hydrostatic Bearing, Spool-Spring System, Dynamic Characteristics

\section{Introduction}

The principle of constant-flow valves are based on that valve resistance can be decreased to compensate the decreasing of difference between supply pressure and recess pressure for keeping flow rate. Rippel (1) has included a DSI type that is named according to double pistons with single feedback and regulating restriction by inlet piston. Bassani and Piccigallo ${ }^{(2)}$ presented another one named DDE type because that is designed as double pistons with double feedbacks and regulation by the piston at exit. The spool-type restrictors can be constant-flow, which regulate restriction by spool and without using flow-meter valve like DDE-type and DSI type. However, the exact constant of flow rate cannot be attained unless selecting appropriate parameters to meet the specific requirement in valve design. Rowe ${ }^{(3)}$ has introduced the mechanism design and written elementary theory of control valves for designing hydrostatic bearings. However, who mainly related the relationships between static characteristics of various bearing types and contact restrictions belong to capillary, slot, orifice, flow control valves, and constant flow pump; pressure-sensing valves. Bassani (4) analyzed that the compensation behaviors of double-action type cylindrical-spool and tapered-spool restrictors for static characteristics of hydrostatic bearings which are installed on slideway, lead screw, thrust bearing, et al. However, his study didn't consider negative and infinite stiffness in the compensation design of hydrostatic bearings. Kang et al. (5) presented the influences of design parameters belonging to the variable compensations of single-action restrictors respectively on static stiffness of hydrostatic bearing and utilized the continuity equations formulated by film flow to study both open-type and closed-type hydrostatic thrust bearings. Kang et al. (6) presented the specific requirements of constant flow rate for various type designs. Kang et al. (7) utilized Runge-Kutta method to investigate the dynamic responses of DSI

[DOl: 10.1299/jamdsm. 7.156] 2012 (№330)

Copyright (C) 2013 by JSME 
types constant-flow valves as working pressure fluctuating. This study uses the same method to simulate the dynamic responses of spool-type constant-flow valves. The influence of design parameters on the deviations of flow rate and spool displacement due to working pressure ratio being fluctuating can be yielded. Also, this paper presented the specific requirement of constant flow rate for this type valves and verified by both analyses and experiments.

\section{Nomenclature}

$\mathrm{A}_{1} \quad$ : projected area of piston $\mathrm{A}_{1}=\pi \mathrm{d}_{\mathrm{p}}^{2} / 4$

$\mathrm{A}_{2}, \overline{\mathrm{A}}_{2} \quad$ : projected area of spool $\mathrm{A}_{2}=\pi \mathrm{d}_{\mathrm{s}}^{2} / 4$ and area ratio $\overline{\mathrm{A}}_{2}=\mathrm{A}_{2} \mathrm{~A}_{1}^{-1}$

$A_{12}, \bar{A}_{12}$ : area difference $A_{12}=A_{1}-A_{2}, \bar{A}_{12}=A_{12} A_{1}^{-1}$

c : damping coefficient

$\mathrm{C}_{\mathrm{s}} \quad$ : displacement coefficient of spool due to action of restoring spring

$\overline{\mathrm{C}}_{\mathrm{s}} \quad$ : dimensionless displacement coefficient $(d d c)$

$d_{n}, d_{s} \quad$ : diameters of valve set and spool

$\mathrm{d}_{\mathrm{p}} \quad$ : actual diameter of piston

$g_{s} \quad$ : spool clearance, $g_{s}=\left(d_{n}-d_{s}\right) / 2$

$\mathrm{k}, \overline{\mathrm{k}} \quad$ : spring constant, dimensionless spring constant $\overline{\mathrm{k}}=\mathrm{k} \ell_{0}\left(\mathrm{P}_{\mathrm{s}} \mathrm{A}_{1}\right)^{-1}$

$\ell_{0} \quad:$ initial restriction length of spool

$P_{r}, P_{r s}, P_{r d}$ : working pressure, the second subscript denotes for static and dynamic parts

$\mathrm{P}_{\mathrm{s}} \quad$ : supply pressure

$\mathrm{P}_{0} \quad$ : equivalent pressure acting on piston by spring preload

$\overline{\mathrm{P}}_{\mathrm{r}}, \overline{\mathrm{P}}_{0} \quad$ : pressure ratio $\overline{\mathrm{P}}=\mathrm{PP}_{\mathrm{s}}^{-1}$

$\mathrm{Q}, \overline{\mathrm{Q}} \quad$ : flow rate, dimensionless flow rate $(d f r) \quad \overline{\mathrm{Q}}=\mathrm{R}_{0} \mathrm{Q} / \mathrm{P}_{\mathrm{s}}$

$\mathrm{Q}_{\mathrm{s}}, \mathrm{Q}_{\mathrm{d}} \quad$ : static and dynamic parts of flow rate

$\overline{\mathrm{Q}}_{\mathrm{d}}^{*} \quad$ : dimensionless amplitude of dynamic flow rate ratio

$\mathrm{R} \quad$ : flow resistance with respect to spool displacement $\mathrm{x}$

$\mathrm{R}_{0} \quad$ : constant of flow resistance with respect to zero displacement of spool

$\mathrm{x}_{\mathrm{s}}, \overline{\mathrm{x}}_{\mathrm{s}} \quad$ : static displacement of spool, $\overline{\mathrm{x}}_{\mathrm{s}}=\mathrm{x}_{\mathrm{s}} \ell_{0}^{-1}$

$\mathrm{x}_{\mathrm{d}}, \overline{\mathrm{x}}_{\mathrm{d}} \quad$ : dynamic displacement of spool, $\overline{\mathrm{x}}_{\mathrm{d}}=\mathrm{x}_{\mathrm{d}} \ell_{0}^{-1}$

$\hat{x}_{d}, \hat{x}_{d}^{*} \quad:$ displacement ratio $\hat{x}_{d}=\bar{x}_{d} / \bar{x}_{s}$, dimensionless amplitude of $\hat{x}_{d}$

$\mathrm{x}_{0}, \overline{\mathrm{x}}_{0} \quad$ : initial deformation of spring due to preload $\overline{\mathrm{x}}_{0}=\mathrm{x}_{0} \ell_{0}^{-1}$

$\alpha \quad$ : dimensionless parameter product $\alpha=\mathrm{R}_{0} \mathrm{~A}_{1} \mathrm{C}_{\mathrm{s}} \omega_{\mathrm{n}}$

$\mu \quad$ : absolute viscosity of oil

$\omega, \omega_{\mathrm{n}} \quad$ : frequency of fluctuating pressure, natural frequency of spool-spring system

$\zeta \quad$ : damping ratio

Subscript

$\mathrm{d}, \mathrm{s} \quad$ : denote for static and dynamic part, respectively of pressures, flow rates, and spool displacements

\section{Principle of Static and Dynamic Flow Rates}

This type valve has the same components and layout of single-action spool-type 
restrictor (3) as shown by Fig. 1. This figure illustrates that the right end of piston is subjected to preload applied by spring and the pressure that is restricted from $\mathrm{P}_{\mathrm{s}}$ applying on the left side of piston. Thus the preload pressure $\mathrm{P}_{0}$ is determined by the resultant force of both actions per piston area. The pressurized oil can flow into inlet and restricted by the cylindrical spool located on left side of piston to leave valve from outlet with working pressure $\mathrm{P}_{\mathrm{r}}$ to a recess of hydrostatic bearing. As soon as $\mathrm{P}_{\mathrm{r}}>\mathrm{P}_{0}$, the spool leaves its initial position which is drawn by dashed lines. The piston locates on the right end and manufactured more smooth than spool surface for sliding and less clearance for sealing. A vent is manufactured on right chamber in order to relief air pressure such as only spring force acts on the piston. The spring can be preloaded by tightening the adjusting screw.

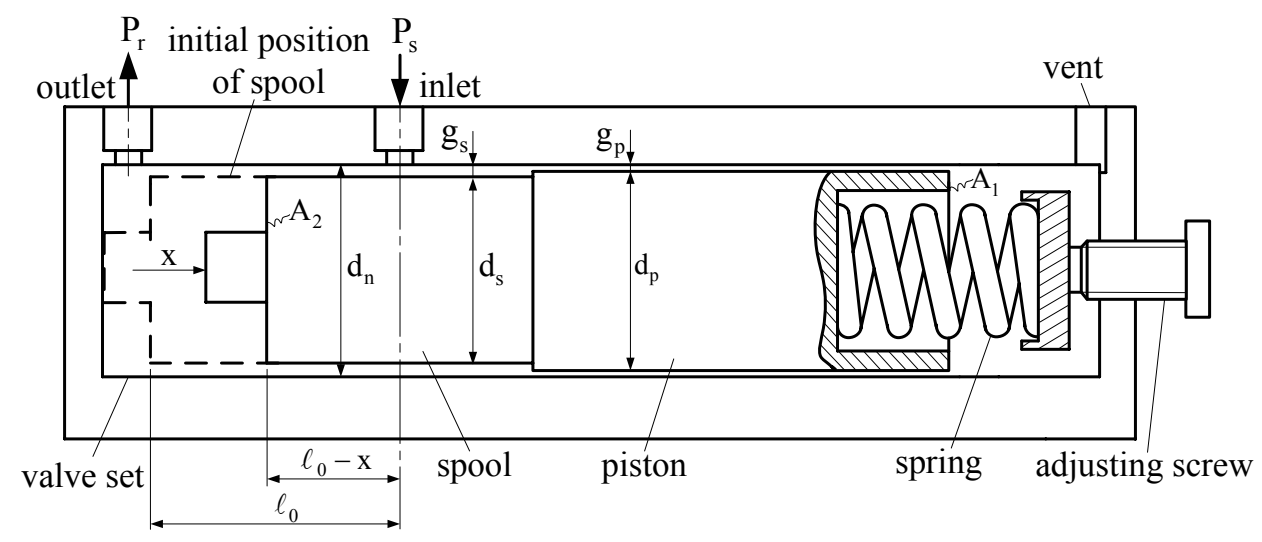

Fig. 1 Design of constant-flow valve

According to basic equation of laminar flow in a circular annul us, the flow rate of this valve can be determined by

$$
\begin{aligned}
\mathrm{Q} & =\frac{\pi \mathrm{d}_{\mathrm{s}} \mathrm{g}_{\mathrm{s}}{ }^{3}}{12 \mu\left(\ell_{0}-\mathrm{x}\right)}\left(\mathrm{P}_{\mathrm{s}}-\mathrm{P}_{\mathrm{r}}\right)-\mathrm{A}_{1} \dot{\mathrm{x}}=\frac{\pi \mathrm{d}_{\mathrm{s}} \mathrm{g}_{\mathrm{s}}{ }^{3} \mathrm{P}_{\mathrm{s}}}{12 \mu \ell_{0}}\left(1-\frac{\mathrm{x}}{\ell_{0}}\right)^{-1}\left(1-\overline{\mathrm{P}}_{\mathrm{r}}\right)-\mathrm{A}_{1} \dot{\mathrm{x}} \\
& =\frac{\mathrm{P}_{\mathrm{s}}\left(1-\overline{\mathrm{P}}_{\mathrm{r}}\right)}{\mathrm{R}_{0}(1-\overline{\mathrm{x}})}-\mathrm{A}_{1} \dot{\mathrm{x}}
\end{aligned}
$$

where $R_{0}=\frac{12 \mu \ell_{0}}{\pi d_{s} g_{s}^{3}}$ is resistance constant of flow passing through the clearance between spool and valve, and $\mathrm{x}$ is spool displacement that is proportional to the net pressure and $\overline{\mathrm{x}}=$ $\mathrm{x} / \ell_{0}$ which can be described by

$$
\overline{\mathrm{x}}=\mathrm{C}_{\mathrm{s}} \ell_{0}^{-1}\left(\mathrm{P}_{\mathrm{r}}-\mathrm{P}_{0}\right)=\mathrm{C}_{\mathrm{s}} \ell_{0}^{-1} \mathrm{P}_{\mathrm{s}}\left(\overline{\mathrm{P}}_{\mathrm{r}}-\overline{\mathrm{P}}_{0}\right)=\overline{\mathrm{C}}_{\mathrm{s}}\left(\overline{\mathrm{P}}_{\mathrm{r}}-\overline{\mathrm{P}}_{0}\right)
$$

where $\overline{\mathrm{C}}_{\mathrm{s}}=\frac{\mathrm{C}_{\mathrm{s}} \mathrm{P}_{\mathrm{s}}}{\ell_{0}}$ is dimensionless displacement coefficient $(d d c)$. Substituting Eq.

into Eq. (1) and divided by $\mathrm{P}_{\mathrm{s}} \mathrm{R}^{-1}$ gives

$$
\overline{\mathrm{Q}}=\frac{\mathrm{R}_{0} \mathrm{Q}}{\mathrm{P}_{\mathrm{s}}}=\frac{1-\overline{\mathrm{P}}_{\mathrm{r}}}{1-\overline{\mathrm{C}}_{\mathrm{s}}\left(\overline{\mathrm{P}}_{\mathrm{r}}-\overline{\mathrm{P}}_{0}\right)}
$$

The function of pre-compression of spring not only give preload $\mathrm{P}_{0}$ to spool but also resist the action of $\mathrm{P}_{\mathrm{s}} \mathrm{A}_{12}$. The spool can just constant valve set without reaction when pressurized lubricant is supplied with $\mathrm{P}_{\mathrm{s}}$ and restricted by spool to apply $\mathrm{P}_{0}$ on the end of spool as shown in Fig. 2. This figure shows that initial equilibrium at working pressure being equal to $\mathrm{P}_{0}$. Thus

$$
\mathrm{P}_{\mathrm{s}} \mathrm{A}_{12}+\mathrm{P}_{0} \mathrm{~A}_{2}=\mathrm{kx}_{0}
$$


From Eq. (4a), we can get

$$
\mathrm{P}_{0}=\mathrm{A}_{2}^{-1}\left(\mathrm{kx}_{0}-\mathrm{P}_{\mathrm{s}} \mathrm{A}_{12}\right)
$$

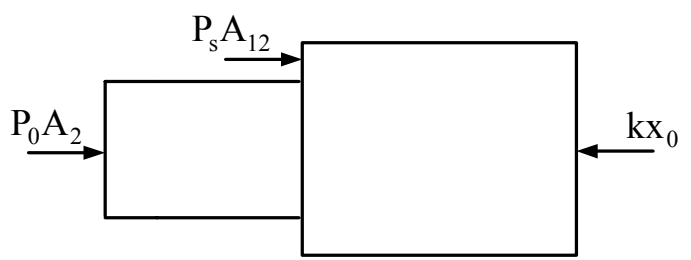

Fig. 2 Equilibrium of static forces applied on spool-piston body.

When $\mathrm{P}_{\mathrm{r}}>\mathrm{P}_{0}$, spool can leave valve set to reduce the restriction length with amount $\mathrm{x}$, the flow resistance can be expressed by

$$
\mathrm{R}=\frac{12 \mu}{\pi \mathrm{d}_{\mathrm{s}} \mathrm{g}_{\mathrm{s}}^{3}}\left(\ell_{0}-\mathrm{x}\right)=\mathrm{R}_{0}(1-\overline{\mathrm{x}})
$$

and displacement ratio of spool is

$$
\overline{\mathrm{x}}=\frac{\mathrm{x}}{\ell_{0}}=\frac{\left(\mathrm{P}_{\mathrm{r}}-\mathrm{P}_{0}\right) \mathrm{A}_{2}}{\mathrm{k} \ell_{0}}=\frac{\mathrm{P}_{\mathrm{s}} \mathrm{A}_{2}\left(\overline{\mathrm{P}}_{\mathrm{r}}-\overline{\mathrm{P}}_{0}\right)}{\mathrm{k} \ell_{0}}=\frac{\overline{\mathrm{P}}_{\mathrm{r}}-\overline{\mathrm{P}}_{0}}{\overline{\mathrm{k}}}=\overline{\mathrm{C}}_{\mathrm{s}}\left(\overline{\mathrm{P}}_{\mathrm{r}}-\overline{\mathrm{P}}_{0}\right)
$$

where $\overline{\mathrm{k}}=\frac{\mathrm{k} \ell_{0}}{\mathrm{P}_{\mathrm{s}} \mathrm{A}_{2}}>\overline{\mathrm{C}}_{\mathrm{s}}^{-1}$ is dimensionless spring constant. The flow rate passing through the restriction length $\ell_{0}-\mathrm{x}$ along spool is

$$
\mathrm{Q}=\frac{\mathrm{P}_{\mathrm{s}}-\mathrm{P}_{\mathrm{r}}}{\mathrm{R}}=\frac{\mathrm{P}_{\mathrm{s}}\left(1-\overline{\mathrm{P}}_{\mathrm{r}}\right)}{\mathrm{R}_{0}(1-\overline{\mathrm{x}})}=\frac{\mathrm{P}_{\mathrm{s}}\left(1-\overline{\mathrm{P}}_{\mathrm{r}}\right)}{\mathrm{R}_{0}\left[1-\overline{\mathrm{C}}_{\mathrm{s}}\left(\overline{\mathrm{P}}_{\mathrm{r}}-\overline{\mathrm{P}}_{0}\right)\right]}-\mathrm{A}_{1} \dot{\mathrm{x}}
$$

From above equation, we can yield dimensionless flow rate as shown by

$$
\overline{\mathrm{Q}}=\frac{\mathrm{R}_{0} \mathrm{Q}}{\mathrm{P}_{\mathrm{s}}}=\frac{1-\overline{\mathrm{P}}_{\mathrm{r}}}{1-\overline{\mathrm{C}}_{\mathrm{s}}\left(\overline{\mathrm{P}}_{\mathrm{r}}-\overline{\mathrm{P}}_{0}\right)}-\frac{\mathrm{R}_{0} \mathrm{~A}_{1}}{\mathrm{P}_{\mathrm{s}}} \dot{\mathrm{x}}
$$

Because working pressure have both static and dynamic parts: $\overline{\mathrm{P}}_{\mathrm{r}}=\overline{\mathrm{P}}_{\mathrm{rs}}+\overline{\mathrm{P}}_{\mathrm{rd}}$, that induce static and dynamic parts of flow rate, substituting $\bar{Q}=\bar{Q}_{s}+\bar{Q}_{d}$ into above equation yields

$$
\overline{\mathrm{Q}}_{\mathrm{s}}+\overline{\mathrm{Q}}_{\mathrm{d}}=\frac{1-\left(\overline{\mathrm{P}}_{\mathrm{rs}}+\overline{\mathrm{P}}_{\mathrm{rd}}\right)}{1-\overline{\mathrm{C}}_{\mathrm{s}}\left(\overline{\mathrm{P}}_{\mathrm{rs}}+\overline{\mathrm{P}}_{\mathrm{rd}}-\overline{\mathrm{P}}_{0}\right)}-\frac{\mathrm{R}_{0} \mathrm{~A}_{1}}{\mathrm{P}_{\mathrm{s}}} \dot{\mathrm{x}}_{\mathrm{d}}
$$

where $\dot{\mathrm{x}}_{\mathrm{d}}$ is the dynamic part of velocity $\dot{\mathrm{x}}$.

\section{Design for Static Flow}

Equation (3) can be expressed for only static part as

$$
\overline{\mathrm{Q}}_{\mathrm{s}}=\frac{1-\overline{\mathrm{P}}_{\mathrm{rs}}}{1-\overline{\mathrm{C}}_{\mathrm{s}}\left(\overline{\mathrm{P}}_{\mathrm{rs}}-\overline{\mathrm{P}}_{0}\right)}
$$

where $\overline{\mathrm{P}}_{\mathrm{rs}}$ denotes for static part. For constant flow $\overline{\mathrm{Q}}_{\mathrm{s}}=$ constant, $\left(1-\overline{\mathrm{P}}_{\mathrm{rs}}\right)$ should be eliminated from both numerator and denominator. The denominator of Eq. (7a) can be rearranged into:

$$
\begin{aligned}
1-\overline{\mathrm{C}}_{\mathrm{s}}\left(\overline{\mathrm{P}}_{\mathrm{rs}}-\overline{\mathrm{P}}_{0}\right)=1-\overline{\mathrm{P}}_{\mathrm{rs}}+\left(1-\overline{\mathrm{C}}_{\mathrm{s}}\right) \overline{\mathrm{P}}_{\mathrm{rs}}+\overline{\mathrm{C}}_{\mathrm{s}} \overline{\mathrm{P}}_{0} \\
=\left(1-\overline{\mathrm{P}}_{\mathrm{rs}}\right)+\overline{\mathrm{C}}_{\mathrm{s}} \overline{\mathrm{P}}_{0}\left(1-\frac{\overline{\mathrm{C}}_{\mathrm{s}}-1}{\overline{\mathrm{C}}_{\mathrm{s}} \overline{\mathrm{P}}_{0}} \overline{\mathrm{P}}_{\mathrm{rs}}\right)
\end{aligned}
$$

where the terms in the second parentheses on the right side of above equation becomes $1-\overline{\mathrm{P}}_{\mathrm{rs}}$ if

$$
\overline{\mathrm{C}}_{\mathrm{s}}-1=\overline{\mathrm{C}}_{\mathrm{s}} \overline{\mathrm{P}}_{0}
$$

Substituting Eq. (4b) into Eq. (8) gives 


$$
\overline{\mathrm{C}}_{\mathrm{s}}-1=\frac{\mathrm{P}_{\mathrm{s}} \mathrm{A}_{2}}{\mathrm{k} \ell_{0}}-1=\frac{\mathrm{P}_{0} \mathrm{~A}_{2}}{\mathrm{k} \ell_{0}}=\frac{\mathrm{kx}_{0}-\mathrm{P}_{\mathrm{s}} \mathrm{A}_{12}}{\mathrm{k} \ell_{0}}=\frac{\mathrm{x}_{0}}{\ell_{0}}-\frac{\mathrm{P}_{\mathrm{s}} \mathrm{A}_{12}}{\mathrm{k} \ell_{0}}
$$

Above equation can be rearranged into

$$
\mathrm{P}_{\mathrm{s}} \mathrm{A}_{1}=\mathrm{k}\left(\ell_{0}+\mathrm{x}_{0}\right)
$$

Thus, the constant flow rate can be yielded as design parameters satisfying Eq. (8b). Furthermore, the condition described by Eq. (8) makes the denominator of Eq. (7a) becomes $\left(1+\overline{\mathrm{C}}_{\mathrm{s}} \overline{\mathrm{P}}_{0}\right)\left(1-\overline{\mathrm{P}}_{\mathrm{rs}}\right)$ and results into

$$
\overline{\mathrm{Q}}_{\mathrm{s}}=\frac{1-\overline{\mathrm{P}}_{\mathrm{rs}}}{\left(1+\overline{\mathrm{C}}_{\mathrm{s}} \overline{\mathrm{P}}_{0}\right)\left(1-\overline{\mathrm{P}}_{\mathrm{rs}}\right)}=\frac{1}{1+\overline{\mathrm{C}}_{\mathrm{s}} \overline{\mathrm{P}}_{0}}=\overline{\mathrm{C}}_{\mathrm{s}}^{-1}=\text { constant }
$$

Then, static flow rate can be yielded as

$$
\mathrm{Q}_{\mathrm{s}}=\frac{\mathrm{P}_{\mathrm{s}} \overline{\mathrm{Q}}_{\mathrm{s}}}{\mathrm{R}}=\frac{\mathrm{P}_{\mathrm{s}}}{\mathrm{R} \overline{\mathrm{C}}_{\mathrm{s}}}=\frac{\pi \mathrm{d}_{\mathrm{s}} \mathrm{g}_{\mathrm{s}}^{3} \mathrm{P}_{\mathrm{s}} \mathrm{k} \ell_{0}}{12 \mu \ell_{0} \mathrm{P}_{\mathrm{s}} \mathrm{A}_{2}}=\frac{\pi \mathrm{d}_{\mathrm{s}} \mathrm{g}_{\mathrm{s}}^{3} \mathrm{k}}{12 \mu \mathrm{A}_{2}}
$$

Furthermore, static displacement of spool can be yielded from Eq. (5b) as shown by

$$
\mathrm{x}_{\mathrm{s}}=\ell_{0} \overline{\mathrm{x}}_{\mathrm{s}}=\ell_{0} \overline{\mathrm{C}}_{\mathrm{s}}\left(\overline{\mathrm{P}}_{\mathrm{rs}}-\overline{\mathrm{P}}_{0}\right)=\mathrm{C}_{\mathrm{s}}\left(\mathrm{P}_{\mathrm{rs}}-\mathrm{P}_{0}\right)
$$

The determinations of Eqs. (8) and (9a) yield that the collocation of $\overline{\mathrm{P}}_{0}$ and $\overline{\mathrm{C}}_{\mathrm{s}}$ for constant flow and corresponding constant of flow rate as shown in Fig. 3. Furthermore, the dimensionless static displacements of spool for various designs as static pressure ratio changing are shown in Fig. 4.

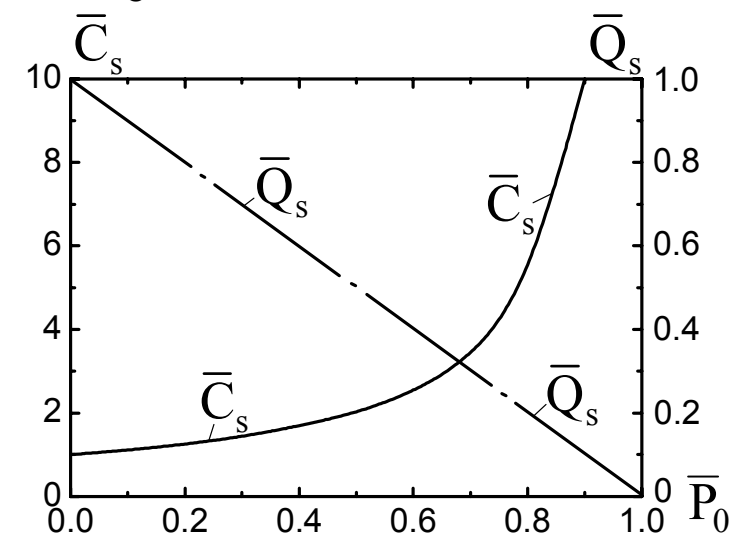

Fig. 3 Dimensionless flow rate $\overline{\mathrm{Q}}_{\mathrm{s}}$ with corresponding collocations of preload $\overline{\mathrm{P}}_{0}$ and dimensionless displacement coefficient

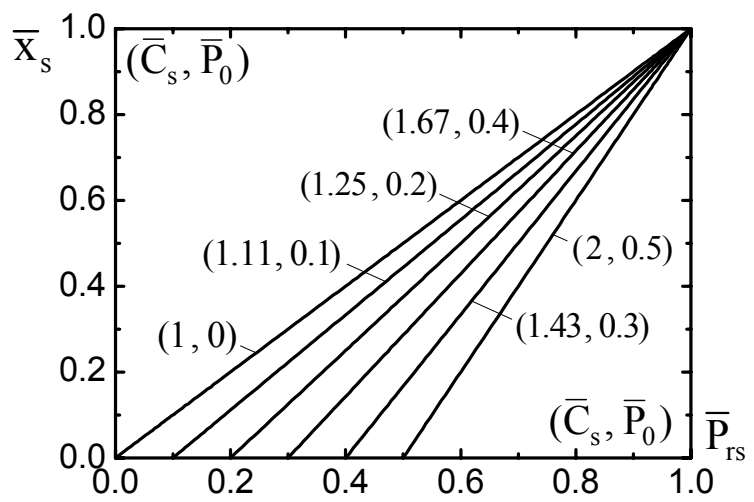

Fig. 4 The dimensionless spool displacement versus $\overline{\mathrm{P}}_{\mathrm{rs}}$ for various designs

We can use a hydrostatic planar bearing to test the valve performance. This bearing has at least three recesses to support a horizontal worktable that is loaded to change recess pressures which are compensated by constant-flow vales individually. The inlet pressures of each recess are controlled to keep constant and the outlet pressures are changed by worktable loads. Both pressures and the temperatures of flow of each recess and the flow 
rates passing through each recess are measured. A practical valve as shown by Fig. 1 is used for experiments. An experimental equipment used in this study as shown in Fig. 5 is composed by a hydrostatic system supplying pressurized oil to recesses of the hydrostatic bearing, and a worktable mounting on the hydrostatic bearing compensated by eight recesses. Four upward recesses compensated by restrictors will be identified are used for calibrating outlet pressure of restrictor and support worktable vertically, and four recesses compensated by constant restrictors and located on the sides of worktable are used only to equilibrate the worktable position in the horizontal directions of both sides. The inlet pressure $P_{s}$ can be calibrated by tuning pressure control valve of supply circuit, and a worktable is used to support load for tuning the outlet pressure of restrictors by changing the recess pressures. The pressures of four recesses can be determined simultaneously by changing load of worktable.

This hydrostatic system utilizes overall and individual accumulators to stabilize pressures in this system. The individual accumulators provide supplied pressures of restrictor inlets that is measured as $\mathrm{P}_{\mathrm{si}}$ for the $\mathrm{i}$-th recess then flow into the $\mathrm{i}$-th recess with outlet pressure $P_{r i}$ and flow rate $Q_{i}$, and finally flow out from the clearance and return to reservoir. The measurement range and sensitivity of pressure meters used to measure the pressures of upstream and downstream of restrictors are $0 \sim 50$ bar and $0.15682 \mathrm{Volt}(\mathrm{kg} / \mathrm{cm})$, respectively, the output is electric current which is necessarily transformed from $4 \sim 20 \mathrm{~mA}$ by resistance $250 \Omega$ to voltage $1 \mathrm{~V} \sim 5 \mathrm{~V}$ for computer input. The measurement range and sensitivity of flow meters used to measure the flow rate of each restrictors are $1 \mathrm{~L} / \mathrm{h} \sim 100 \mathrm{~L} / \mathrm{h}$ and 0.006253 Volt $(\mathrm{cm} / \mathrm{min})$, respectively, the output is voltage from 0 to 10 Volt with error $\pm 0.5 \% \sim \pm 1 \%$. The IC type temperature sensors are used with thermometers and amplifier AD590J, which have the measurement range and sensitivity are $-55 \sim 150{ }^{\circ} \mathrm{C}$ and $1 \mu \mathrm{A} /{ }^{\circ} \mathrm{K}$ respectively, the output is voltage from 0 to 10 Volt corresponding to the temperature range from 0 to $100{ }^{\circ} \mathrm{C}$ with repeatable accuracy $\pm 0.1^{\circ} \mathrm{C}$.

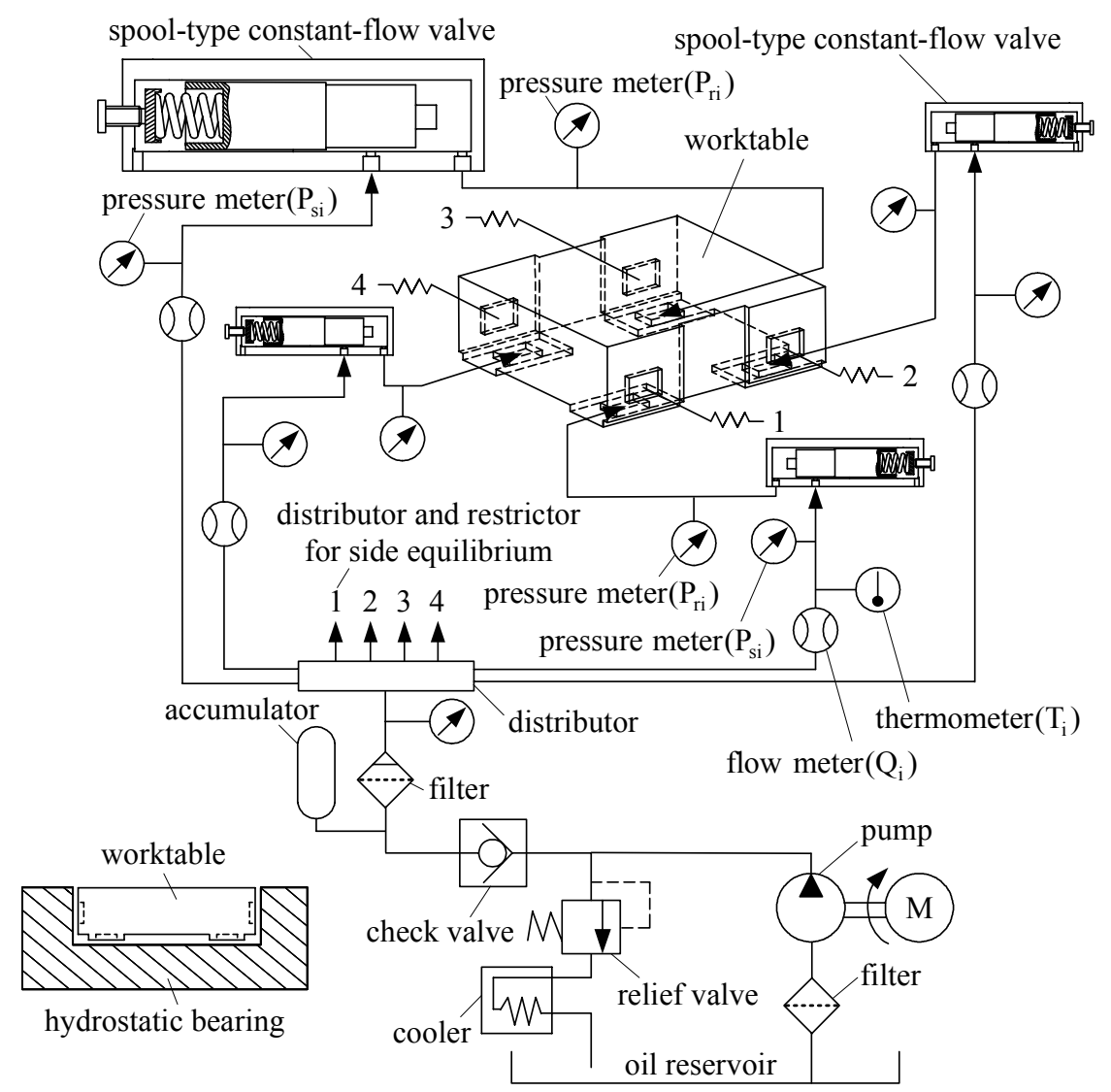

Fig. 5 Experimental equipment.

The valve used for experiments has fixed parameters as given by $\mathrm{d}_{\mathrm{s}}=3.155 \mathrm{~cm}$, $\mathrm{d}_{\mathrm{p}}=3.198 \mathrm{~cm}, \mathrm{~d}_{\mathrm{n}}=3.2025 \mathrm{~cm}, \mathrm{~g}_{\mathrm{s}}=0.2375 \mathrm{~mm}, \mathrm{~A}_{1}=8.0324 \mathrm{~cm}^{2}, \mathrm{~A}_{2}=7.814 \mathrm{~cm}^{2}$, set 
$\ell_{0}=3.891 \mathrm{~cm}$, lubricant SAE 20 with absolute viscosity for typical average temperature between outlet and inlet at $20.5^{\circ} \mathrm{C}$ which is kept at the inlet of valves.

Experiment 1

Other design parameters $\mathrm{k}=18.4 \mathrm{Kg} / \mathrm{cm}, \mathrm{x}_{0}=3 \mathrm{~mm}$, and $\mu=0.16 \mathrm{~Pa} \cdot \mathrm{s}$ are given, substituting these parameters into Eqs. (8b) and (9b) to determine the supply pressure of constant flow valve respectively by

$$
\mathrm{P}_{\mathrm{s}}=\mathrm{k}\left(\ell_{0}+\mathrm{x}_{0}\right) \mathrm{A}_{1}^{-1}=\frac{18.4(3.891+0.3)}{8.0324}=9.6 \mathrm{Kg} / \mathrm{cm}^{2}
$$

and

$$
\mathrm{Q}=\frac{\pi \mathrm{d}_{\mathrm{s}} \mathrm{g}_{\mathrm{s}}^{3} \mathrm{k}}{12 \mu \mathrm{A}_{2}}=\frac{3.14 \times 3.155 \times 0.02375^{3} \times 18.4 \times 9.8}{12 \times 0.16 \times 10^{-4} \times 7.814} \frac{\mathrm{cm}^{3}}{\mathrm{~s}}=957.1 \mathrm{~cm}^{3} / \mathrm{min}
$$

According to results measured from the test as mentioned above, the constant flow as shown in Fig. 6 can be obtained as supply pressure is $9.6 \mathrm{Kg} / \mathrm{cm}^{2}$. In this figure, the flow rate keeps almost constant as $\mathrm{P}_{\mathrm{r}}$ varying or loading is changed. The variations of supply pressure and both temperatures are shown also. Constant flow cannot be attained other than supply pressures being $9.6 \mathrm{Kg} / \mathrm{cm}^{2}$. Fig. 7 shows that the variations of both temperatures and flow rate with respect to load changing from 0 to $200 \mathrm{Kg}$ with $20 \mathrm{Kg}$ increment by using supply pressures $7 \cdot 8 \cdot 9 \cdot 10 \mathrm{Kg} / \mathrm{cm}^{2}$. Both figures reveal that the flow rate is influenced by temperatures variety mainly and supply pressure can be kept with small error less than $1 \%$.
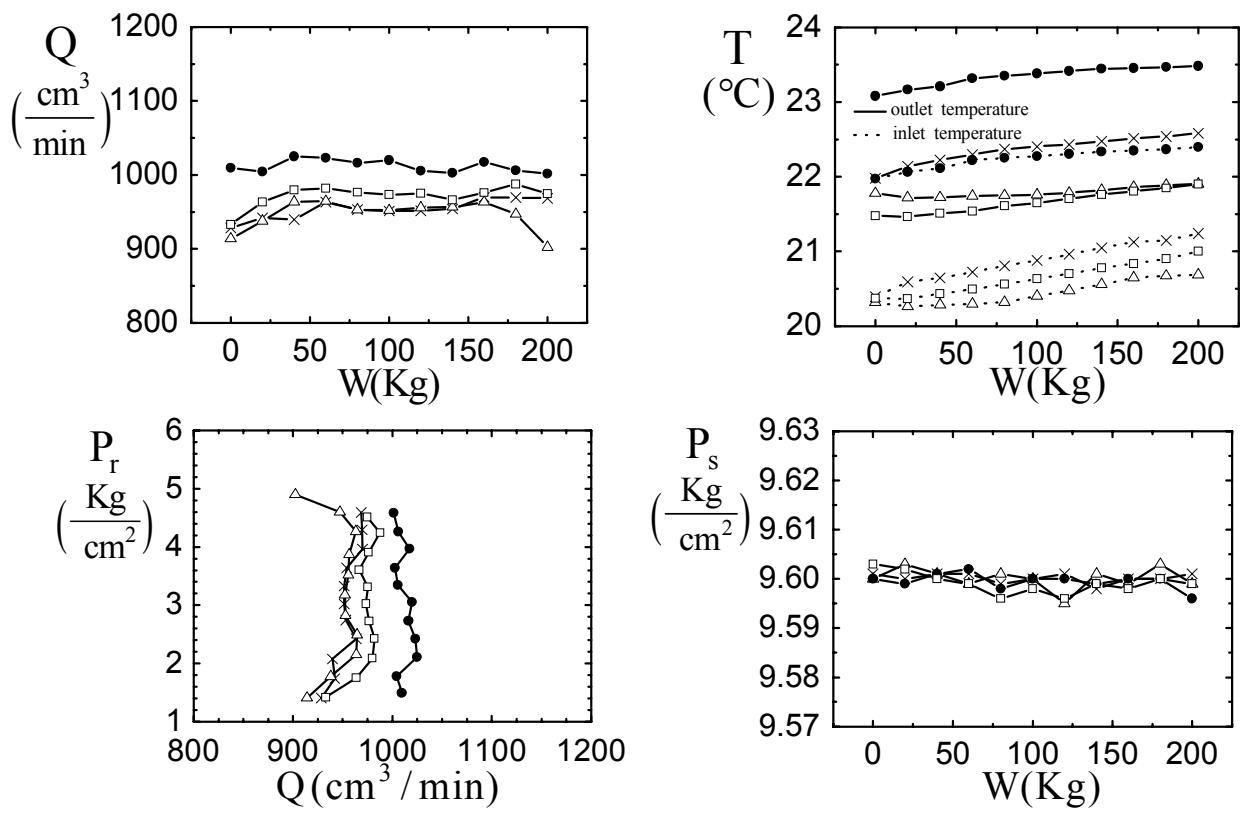

Fig. 6 The variations of (a) flow rate and (b) both temperatures with respect to load changing from 0 to $200 \mathrm{Kg}$ with $20 \mathrm{Kg}$ increment and (c) pressure ratio of recess and (d) supply pressure of nominal $9.6 \mathrm{Kg} / \mathrm{cm}^{2}\left(\times: 1^{\text {st }}\right.$ measurement, $\triangle: 2^{\text {nd }}$ measurement, $\bullet: 3^{\text {rd }}$ measurement, $\square: 4^{\text {th }}$ measurement)

Experiment 2

Other design parameters $\mathrm{k}=26 \mathrm{Kg} / \mathrm{cm}, \mathrm{x}_{0}=1 \mathrm{~mm}$, and $\mu=0.18 \mathrm{~Pa} \cdot \mathrm{s}$ are given, substituting these parameters into Eqs. (8b) and (9b) to determine the supply pressure of constant flow valve respectively by

$$
\mathrm{P}_{\mathrm{s}}=\mathrm{k}\left(\ell_{0}+\mathrm{x}_{0}\right) \mathrm{A}_{1}^{-1}=\frac{26(3.891+0.1)}{8.0324}=12.92 \mathrm{Kg} / \mathrm{cm}^{2}
$$

and

$$
\mathrm{Q}=\frac{\pi \mathrm{d}_{\mathrm{s}} \mathrm{g}_{\mathrm{s}}^{3} \mathrm{k}}{12 \mu \mathrm{A}_{2}}=\frac{3.14 \times 3.155 \times 0.02375^{3} \times 26 \times 9.8}{12 \times 0.18 \times 10^{-4} \times 7.814} \frac{\mathrm{cm}^{3}}{\mathrm{~s}}=1202.1 \mathrm{~cm}^{3} / \mathrm{min}
$$



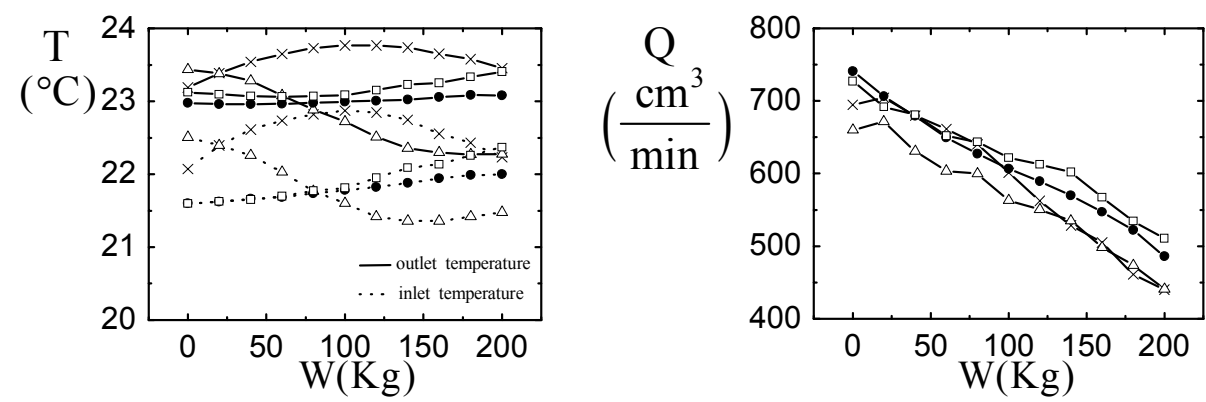

Supply pressure: $7 \pm 0.02 \mathrm{Kg} / \mathrm{cm}^{2}$
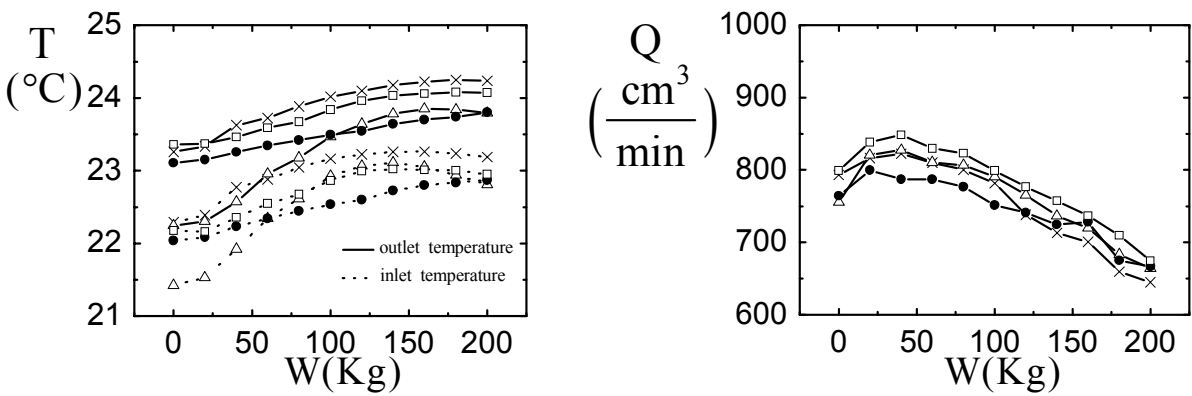

Supply pressure: $8 \pm 0.02 \mathrm{Kg} / \mathrm{cm}^{2}$
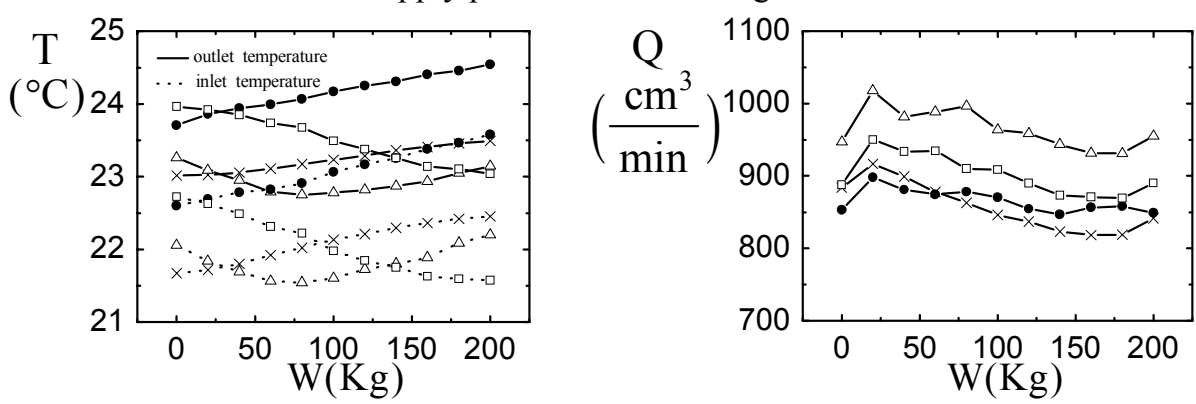

Supply pressure: $9 \pm 0.02 \mathrm{Kg} / \mathrm{cm}^{2}$
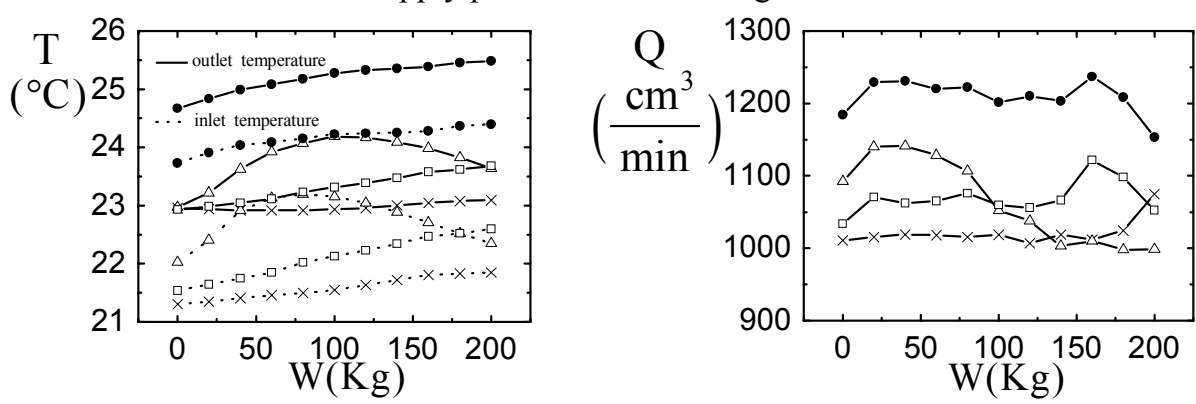

Supply pressure: $10 \pm 0.02 \mathrm{Kg} / \mathrm{cm}^{2}$

Fig. 7 The variations of both temperatures and flow rate with respect to load changing from 0 to $200 \mathrm{Kg}$ with $20 \mathrm{Kg}$ increment for experiment 1 by using supply pressures $7 \cdot 8$.

$9 \cdot 10 \mathrm{Kg} / \mathrm{cm}^{2}\left(\times: 1^{\text {st }}\right.$ measurement, $: 2^{\text {nd }}$ measurement, $\bullet: 3^{\text {rd }}$ measurement, $\square: 4^{\text {th }}$ measurement)

According to results measured from the test as mentioned above, the variations of both temperatures and flow rate with respect to load changing from 0 to $200 \mathrm{Kg}$ with $20 \mathrm{Kg}$ increment by using supply pressures $12,12.5,13$, and $14 \mathrm{Kg} / \mathrm{cm}^{2}$ are shown in Figure 8 . The constant flow as shown in Fig. 8(c) can be obtained as supply pressure is $13 \mathrm{Kg} / \mathrm{cm}^{2}$. Constant flow cannot be attained or larger variations of flow rate as load change other than supply pressures being $13 \mathrm{Kg} / \mathrm{cm}^{2}$. This experiment reveals that supply pressure can be kept with small error less than $1 \%$ and shows also that the flow rate is influenced by temperatures variety mainly. 

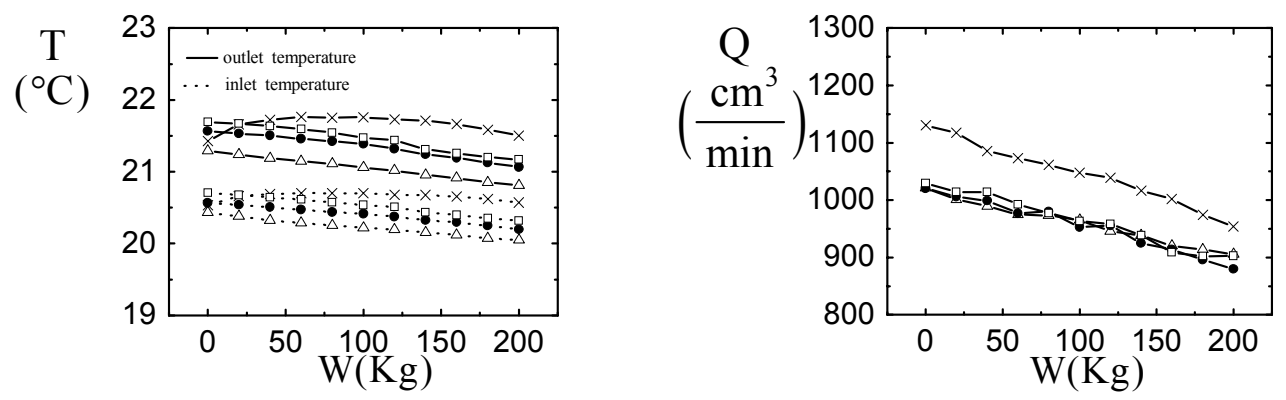

Supply pressure: $12 \pm 0.02 \mathrm{Kg} / \mathrm{cm}^{2}$
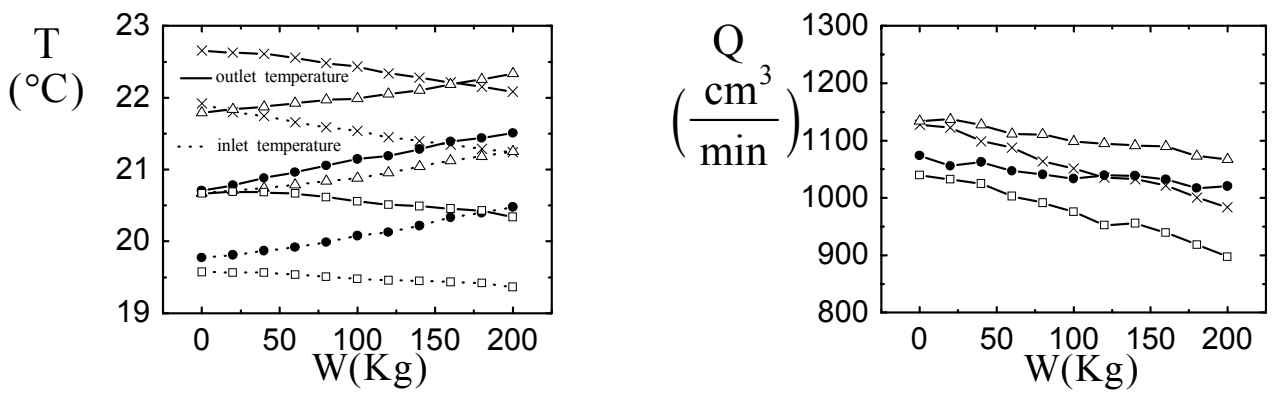

Supply pressure: $12.5 \pm 0.02 \mathrm{Kg} / \mathrm{cm}^{2}$
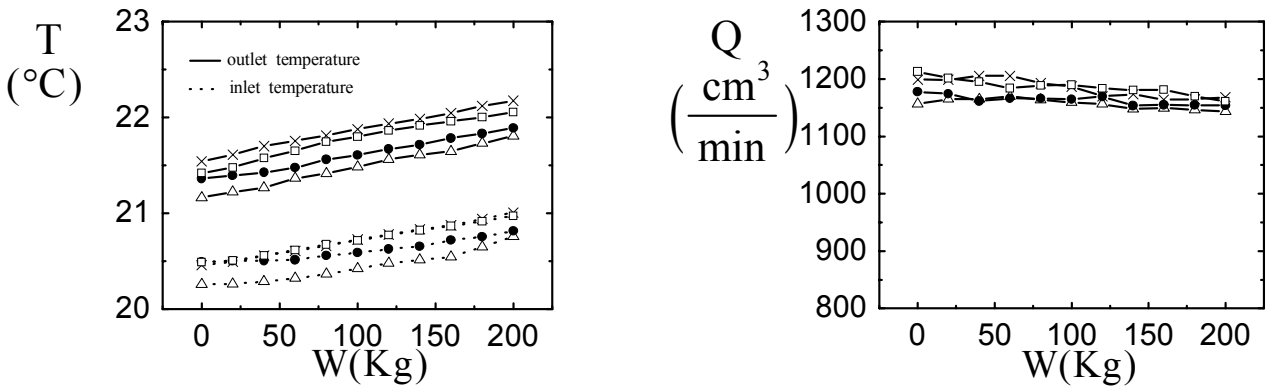

Supply pressure: $13 \pm 0.01 \mathrm{Kg} / \mathrm{cm}^{2}$
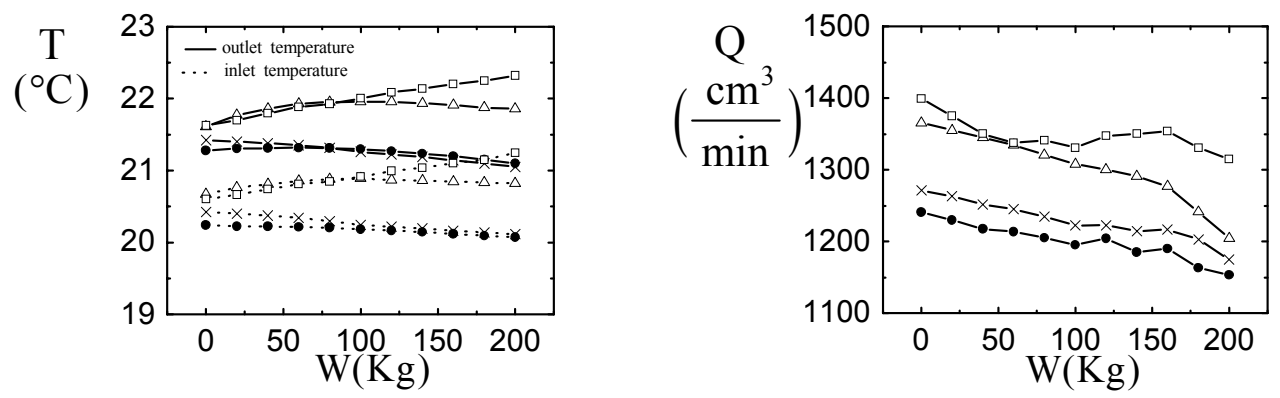

Supply pressure: $14 \pm 0.02 \mathrm{Kg} / \mathrm{cm}^{2}$

Fig. 8 The variations of both temperatures and flow rate with respect to load changing from 0 to $200 \mathrm{Kg}$ with $20 \mathrm{Kg}$ increment for experiment 2 by using various supply pressures $\left(\times: 1^{\text {st }}\right.$ measurement, $\triangle: 2^{\text {nd }}$ measurement, $\bullet: 3^{\text {rd }}$ measurement, $\square: 4^{\text {th }}$ measurement $)$

\section{Dynamic characteristics}

From dynamic equilibrium as shown in Fig. 8, the motion equation of spool is expressed by

$$
\begin{gathered}
m \ddot{x}_{d}+\dot{x}_{d}+k_{d}=P_{r d} A_{2} \\
\text { Using } \hat{x}_{d}=x_{d} / x_{s}, \omega_{n}=\sqrt{\frac{k}{m}}, \tau=\omega_{n} t, \quad \bar{\omega}=\omega / \omega_{n}, \quad \zeta=\frac{c}{2 m \omega_{n}}, \bar{k}=\frac{k \ell_{0}}{P_{s} A_{2}}, \\
\frac{d x_{d}}{d t}=x_{s} \omega_{n} \frac{d \hat{x}_{d}}{d \tau} \text { 及 } \frac{d^{2} x_{d}}{d^{2}}=x_{s} \omega_{n}^{2} \frac{d^{2} \hat{x}_{d}}{d \tau^{2}}, \text { above equation can be expressed in }
\end{gathered}
$$




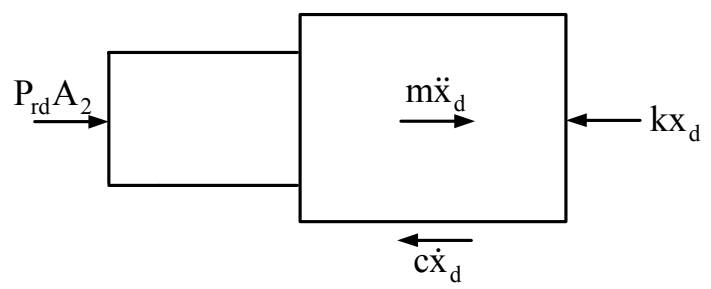

Fig. 9 Equilibrium of dynamic forces

dimensionless form as

$$
\ddot{\hat{\mathrm{x}}}_{\mathrm{d}}+2 \zeta \dot{\hat{\mathrm{x}}}_{\mathrm{d}}+\hat{\mathrm{x}}_{\mathrm{d}}=\left(\overline{\mathrm{k}} \overline{\mathrm{x}}_{\mathrm{s}}\right)^{-1} \overline{\mathrm{P}}_{\mathrm{rd}}=\overline{\mathrm{C}}_{\mathrm{s}} \overline{\mathrm{x}}_{\mathrm{s}}^{-1} \overline{\mathrm{P}}_{\mathrm{rd}}
$$

When $\overline{\mathrm{P}}_{\mathrm{rd}}=\overline{\mathrm{P}}_{\mathrm{rd}}^{*} \sin \bar{\omega} \tau$

$$
\begin{aligned}
& \hat{\mathrm{x}}_{\mathrm{d}}=\hat{\mathrm{x}}_{\mathrm{dc}}^{*} \cos \bar{\omega} \tau+\hat{\mathrm{x}}_{\mathrm{ds}}^{*} \sin \bar{\omega} \tau \\
& \dot{\hat{\mathrm{x}}}_{\mathrm{d}}=\bar{\omega}\left(-\hat{\mathrm{x}}_{\mathrm{dc}}^{*} \sin \bar{\omega} \tau+\hat{\mathrm{x}}_{\mathrm{ds}}^{*} \cos \bar{\omega} \tau\right) \\
& \ddot{\hat{\mathrm{x}}}_{\mathrm{d}}=-\bar{\omega}^{2}\left(\hat{\mathrm{x}}_{\mathrm{dc}}^{*} \cos \bar{\omega} \tau+\hat{\mathrm{x}}_{\mathrm{ds}}^{*} \sin \bar{\omega} \tau\right)
\end{aligned}
$$

Substituting above $\hat{\mathrm{x}}_{\mathrm{d}}$ and its derivatives into Eq. (11b) gives

$$
\begin{aligned}
& {\left[\left(1-\bar{\omega}^{2}\right) \hat{\mathrm{x}}_{\mathrm{dc}}^{*}+2 \zeta \bar{\omega} \hat{\mathrm{x}}_{\mathrm{ds}}^{*}\right] \cos \bar{\omega} \tau+\left[-2 \zeta \bar{\omega} \hat{\mathrm{x}}_{\mathrm{dc}}^{*}+\left(1-\bar{\omega}^{2}\right) \hat{\mathrm{x}}_{\mathrm{ds}}^{*}\right] \sin \bar{\omega} \tau } \\
= & \overline{\mathrm{C}}_{\mathrm{s}} \overline{\mathrm{x}}_{\mathrm{s}}^{-1} \overline{\mathrm{P}}_{\mathrm{rd}}^{*} \sin \bar{\omega} \tau \\
& {\left[\begin{array}{cc}
1-\bar{\omega}^{2} & 2 \zeta \bar{\omega} \\
-2 \zeta \bar{\omega} & 1-\bar{\omega}^{2}
\end{array}\right]\left[\begin{array}{c}
\hat{\mathrm{x}}_{\mathrm{dc}}^{*} \\
\hat{\mathrm{x}}_{\mathrm{ds}}^{*}
\end{array}\right]=\left[\begin{array}{c}
0 \\
\overline{\mathrm{C}}_{\mathrm{s}} \overline{\mathrm{x}}_{\mathrm{s}}^{-1} \overline{\mathrm{P}}_{\mathrm{rd}}^{*}
\end{array}\right] } \\
& \Delta=\left(1-\bar{\omega}^{2}\right)^{2}+4 \zeta^{2} \bar{\omega}^{2} \\
& \hat{\mathrm{x}}_{\mathrm{dc}}^{*}=-2 \zeta \bar{\omega} \overline{\mathrm{C}}_{\mathrm{s}} \overline{\mathrm{x}}_{\mathrm{s}}^{-1} \overline{\mathrm{P}}_{\mathrm{rd}}^{*}\left[\left(1-\bar{\omega}^{2}\right)^{2}+4 \zeta^{2} \bar{\omega}^{2}\right]^{-1} \\
& \hat{\mathrm{x}}_{\mathrm{ds}}^{*}=\left(1-\bar{\omega}^{2}\right) \overline{\mathrm{C}}_{\mathrm{s}} \overline{\mathrm{x}}_{\mathrm{s}}^{-1} \overline{\mathrm{P}}_{\mathrm{rd}}^{*}\left[\left(1-\bar{\omega}^{2}\right)^{2}+4 \zeta^{2} \bar{\omega}^{2}\right]^{-1} \\
& \sqrt{\left(\hat{\mathrm{x}}_{\mathrm{dc}}\right)^{*}+\left(\hat{\mathrm{x}}_{\mathrm{ds}}^{*}\right)^{2}}=\overline{\mathrm{C}}_{\mathrm{s}} \overline{\mathrm{x}}_{\mathrm{s}}^{-1} \overline{\mathrm{P}}_{\mathrm{rd}}^{*}\left[\left(1-\bar{\omega}^{2}\right)^{2}+4 \zeta^{2} \bar{\omega}^{2}\right]^{\frac{-1}{2}}, \phi=\frac{2 \zeta \bar{\omega}}{1-\bar{\omega}^{2}}
\end{aligned}
$$

The harmonic solution can be yielded as

$$
\hat{\mathrm{x}}_{\mathrm{d}}=\overline{\mathrm{C}}_{\mathrm{s}} \overline{\mathrm{x}}_{\mathrm{s}}^{-1} \overline{\mathrm{P}}_{\mathrm{rd}}^{*}\left[\left(1-\bar{\omega}^{2}\right)^{2}+4 \zeta^{2} \bar{\omega}^{2}\right]^{\frac{-1}{2}} \sin (\bar{\omega} \tau+\phi)
$$

Thus, the amplitude and phase of dynamic response $\hat{x}_{d}$ are

$$
\begin{aligned}
& \hat{\mathrm{x}}_{\mathrm{d}}^{*}=\overline{\mathrm{C}}_{\mathrm{s}} \overline{\mathrm{x}}_{\mathrm{s}}^{-1} \overline{\mathrm{P}}_{\mathrm{rd}}^{*}\left[\left(1-\bar{\omega}^{2}\right)^{2}+4 \zeta^{2} \bar{\omega}^{2}\right]^{\frac{-1}{2}} \\
& \phi=\frac{2 \zeta \bar{\omega}}{1-\bar{\omega}^{2}}
\end{aligned}
$$

Differentiating Eq. (13) with respect to time gives velocity of $\hat{x}_{d}$ as shown by

$$
\dot{\hat{\mathrm{x}}}_{\mathrm{d}}=\overline{\mathrm{C}}_{\mathrm{s}} \overline{\mathrm{x}}_{\mathrm{s}}^{-1} \overline{\mathrm{P}}_{\mathrm{rd}}^{*} \bar{\omega}\left[\left(1-\bar{\omega}^{2}\right)^{2}+4 \zeta^{2} \bar{\omega}^{2}\right]^{\frac{-1}{2}} \cos (\bar{\omega} \tau+\phi)
$$

Since $\frac{1-\left(\overline{\mathrm{P}}_{\mathrm{rs}}+\overline{\mathrm{P}}_{\mathrm{rd}}\right)}{1-\overline{\mathrm{C}}_{\mathrm{s}}\left(\overline{\mathrm{P}}_{\mathrm{rs}}+\overline{\mathrm{P}}_{\mathrm{rd}}-\overline{\mathrm{P}}_{0}\right)}=\overline{\mathrm{C}}_{\mathrm{s}}^{-1}$, substituting Eqs. (8) and (15) into Eq. (6c) gives the dynamic response of flow rate due to working pressure fluctuating as shown:

$$
\overline{\mathrm{Q}}_{\mathrm{d}}=-\alpha \overline{\mathrm{P}}_{\mathrm{rd}}^{*} \frac{\bar{\omega} \cos (\bar{\omega} \tau+\phi)}{\sqrt{\left(1-\bar{\omega}^{2}\right)^{2}+4 \zeta^{2} \bar{\omega}^{2}}}
$$


where $\alpha=\mathrm{R}_{0} \mathrm{~A}_{1} \mathrm{C}_{\mathrm{s}} \omega_{\mathrm{n}}$. Consequently, the relationship of amplitudes of dynamic responses between flow rate and spool displacement can be obtained by substituting Eq. (14a) into Eq. (16a) and shown by

$$
\overline{\mathrm{Q}}_{\mathrm{d}}^{*}=\alpha \hat{\mathrm{x}}_{\mathrm{d}}^{*} \overline{\mathrm{x}}_{\mathrm{s}} \overline{\mathrm{C}}_{\mathrm{s}}^{-1} \bar{\omega}
$$

which reveals that the amplitude of dynamic flow rate is proportional to the product of spool amplitude and fluctuating frequency. Dimensionless parameters for various designs of the spool-type constant-flow valve are shown in Table 1.

Table 1 Dimensionless parameters of six design cases

\begin{tabular}{l|cccccc} 
& Case 1 & Case 2 & Case 3 & Case 4 & Case 5 & Case 6 \\
\hline$\overline{\mathrm{P}}_{0}$ & 0 & 0.1 & 0.2 & 0.3 & 0.4 & 0.5 \\
$\overline{\mathrm{C}}_{\mathrm{s}}$ & 1 & 1.11 & 1.25 & 1.43 & 1.67 & 2 \\
$\overline{\mathrm{Q}}_{\mathrm{s}}$ & 1 & 0.9 & 0.8 & 0.7 & 0.6 & 0.5
\end{tabular}
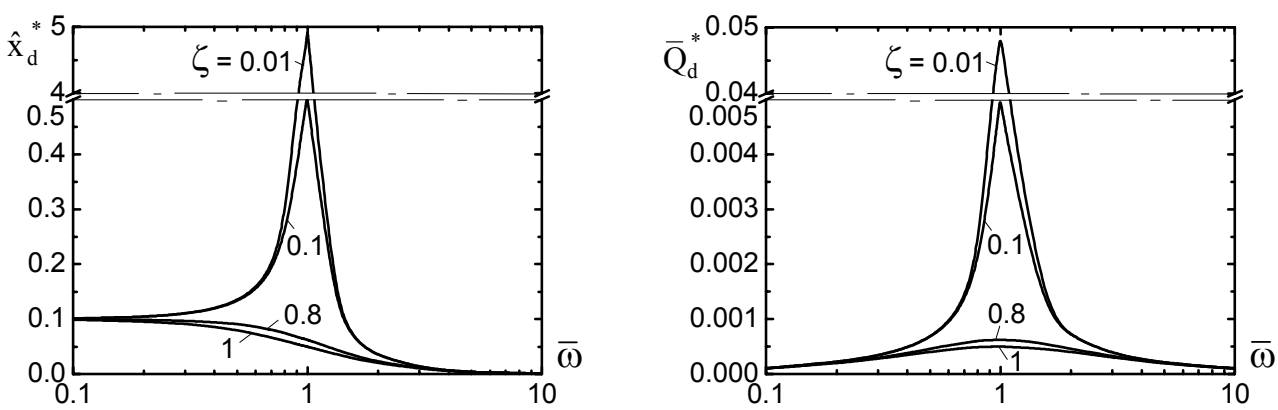

(a) $\overline{\mathrm{P}}_{\mathrm{rs}}=0.1$
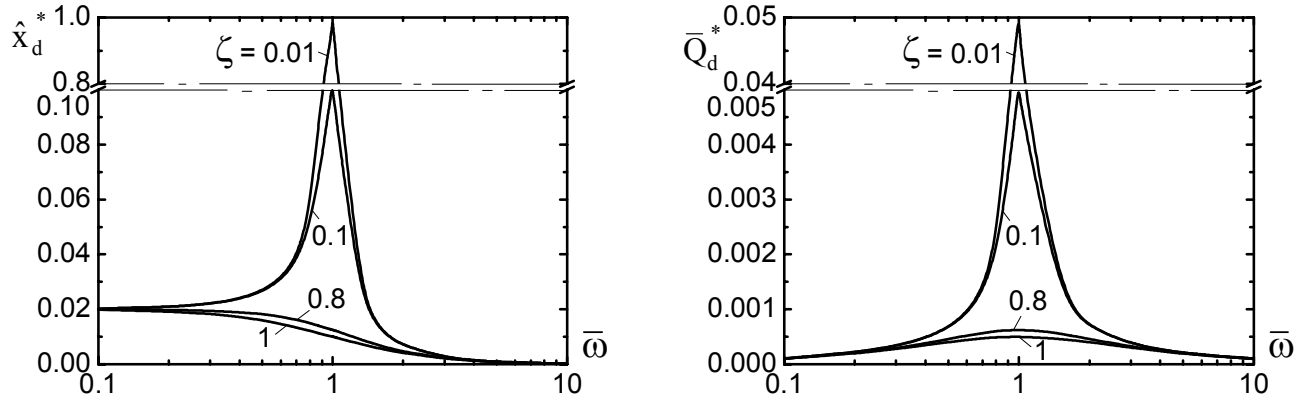

(b) $\overline{\mathrm{P}}_{\mathrm{rs}}=0.5$
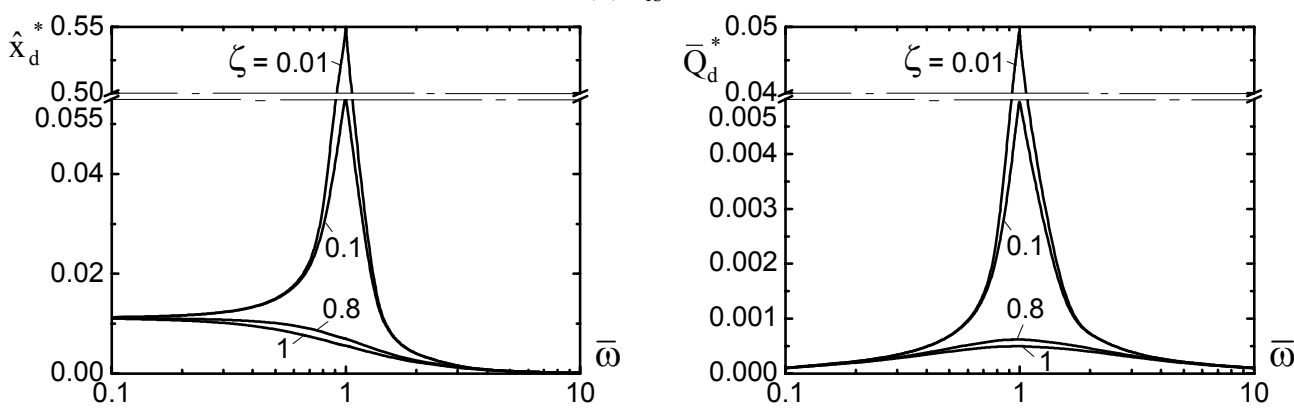

(c) $\overline{\mathrm{P}}_{\mathrm{rs}}=0.9$

Fig. 10 Amplitudes of $\hat{x}_{d}$ and $\bar{Q}_{d}$ for case $1\left(\bar{Q}_{s}=1\right)$ as $\bar{P}_{r d}^{*}=0.01$ 

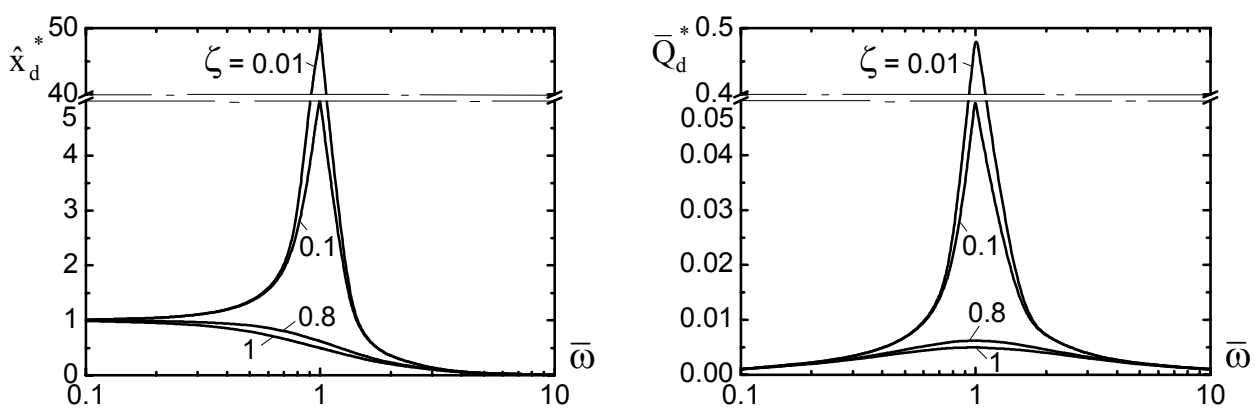

(a) $\overline{\mathrm{P}}_{\mathrm{rs}}=0.1$
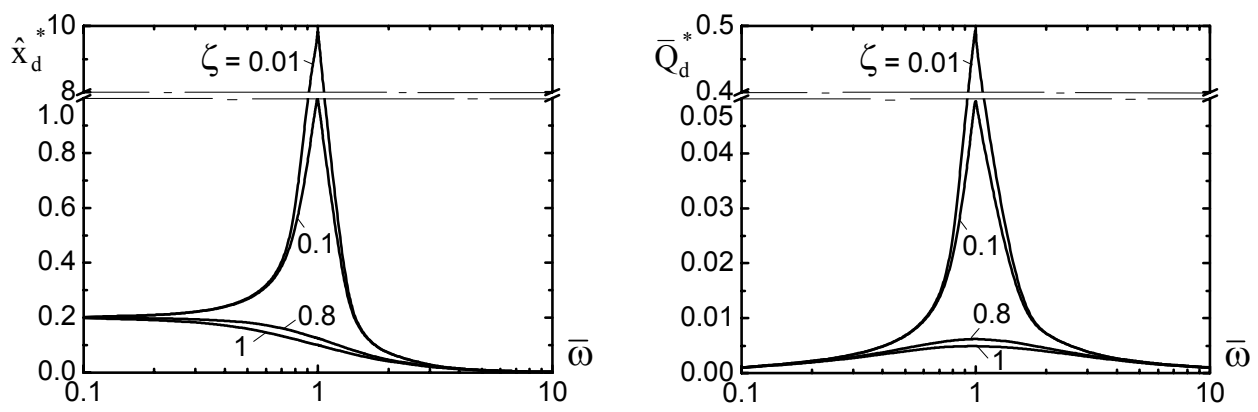

(b) $\overline{\mathrm{P}}_{\mathrm{rs}}=0.5$
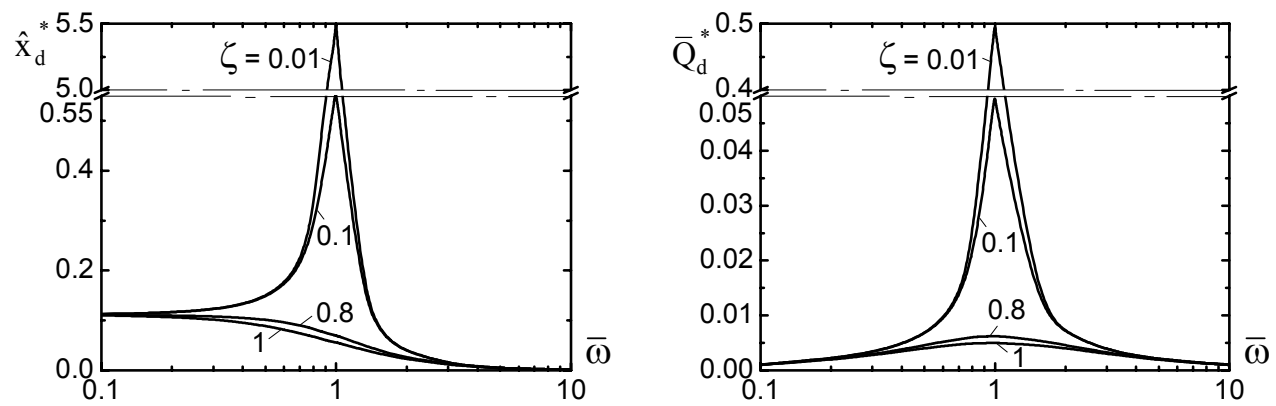

(c) $\overline{\mathrm{P}}_{\mathrm{rs}}=0.9$

Fig. 11 Amplitudes of $\hat{x}_{d}$ and $\bar{Q}_{d}$ for case $1\left(\bar{Q}_{s}=1\right)$ as $\overline{\mathrm{P}}_{\mathrm{rd}}^{*}=0.1$

The analytical results of case 1 subjected to various static pressure ratios are illustrated in Figs. 10 and 11 for $\overline{\mathrm{P}}_{\mathrm{rd}}^{*}=0.01$ and 0.1 , respectively. Dimensionless parameter product $\alpha=0.1$ and damping ratios $\zeta=0.01,0.1,0.8$, and 1 are selected to determine.

In both figures, the amplitudes of spool displacement and flow rate are shown on left and right column, respectively. Which show that the amplitude of spool displacement is suppressed by static pressure ratio but proportional to the amplitude of dynamic pressure ratio. The amplitude of flow rate cannot be influenced by static pressure ratio but can be influenced by damping ratio, excitation frequency and proportional to the amplitude of dynamic pressure ratio.

The analytical results of cases 4 and 5 subjected to static pressure ratios $\overline{\mathrm{P}}_{\mathrm{rd}}{ }^{*}=0.01$ are illustrated in Figs. 12 and 13, respectively. Dimensionless parameter product $\alpha=0.1$ and damping ratios $\zeta=0.01,0.1,0.8$, and 1 for both cases are selected also. Both figures reveal not only the same behavior as shown by Figs. 11 and 12 but also show that the amplitude of spool displacement can increase as static flow rate is decreasing but the amplitude of flow rate cannot be influenced by static flow rate. 

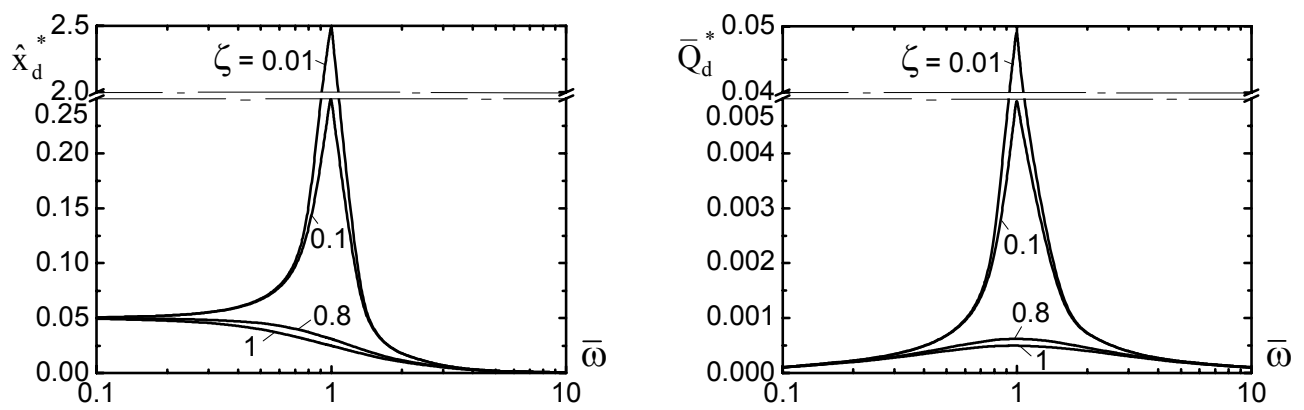

(a) $\overline{\mathrm{P}}_{\mathrm{rs}}=0.5$
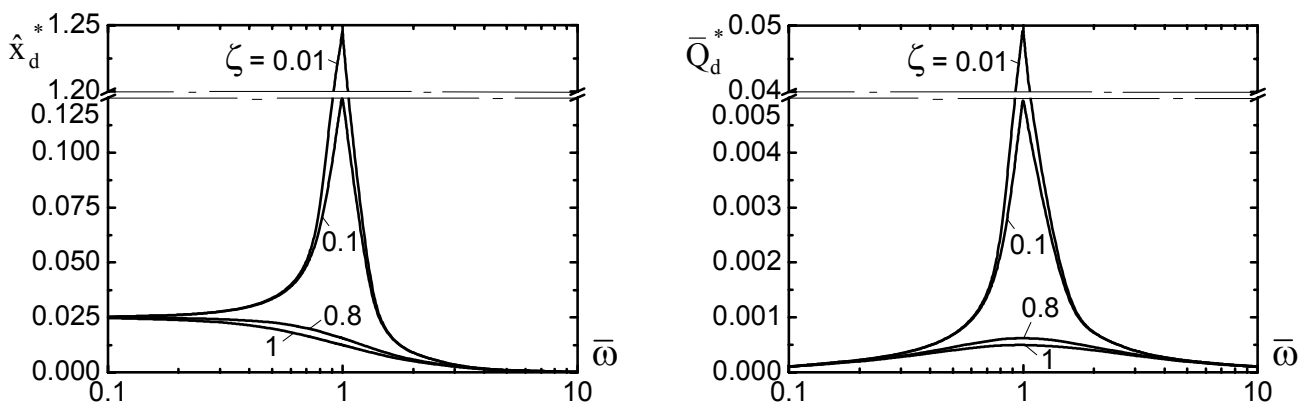

(b) $\overline{\mathrm{P}}_{\mathrm{rs}}=0.7$
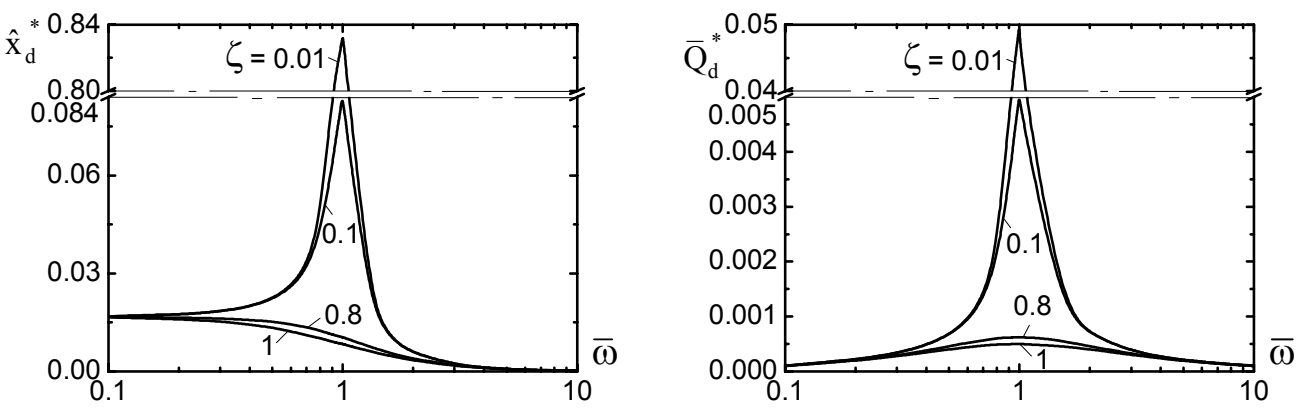

(c) $\overline{\mathrm{P}}_{\mathrm{rs}}=0.9$

Fig. 12 Amplitudes of $\hat{x}_{d}$ and $\bar{Q}_{d}$ for case $4\left(\bar{Q}_{s}=0.7\right)$ as $\bar{P}_{r d}^{*}=0.01$

From Fig. 10 to 13 reveals that (1) the resonance occurs as excitation frequency is close to the natural frequency of the spool-spring system, which induces large amplitudes of $\hat{\mathrm{x}}_{\mathrm{d}}$ and $\overline{\mathrm{Q}}_{\mathrm{d}}$, when damping ratio is smaller than 1, (2) in companions of Figs. 10, 12, and 13 for a specific $\overline{\mathrm{P}}_{\mathrm{rd}}^{*}, \hat{\mathrm{x}}_{\mathrm{d}}^{*}$ gets smaller as $\overline{\mathrm{Q}}_{\mathrm{s}}$ is increasing, but $\overline{\mathrm{Q}}_{\mathrm{d}}^{*}$ can be invariant as $\overline{\mathrm{Q}}_{\mathrm{s}}$ changes, (3) resonant peaks of both $\hat{\mathrm{x}}_{\mathrm{d}}^{*}$ and $\overline{\mathrm{Q}}_{\mathrm{d}}^{*}$ are reduced as damping is increasing, when damping ratio $\zeta \geq 1$ resonant peaks are suppressed to disappear, (4) $\hat{\mathrm{x}}_{\mathrm{d}}^{*}$ gets larger as $\bar{\omega}$ is decreasing, but maximum of $\overline{\mathrm{Q}}_{\mathrm{d}}^{*}$ presents near natural frequency since $\overline{\mathrm{Q}}_{\mathrm{d}}^{*}$ is proportional to the product of $\bar{\omega}$ and $\hat{\mathrm{x}}_{\mathrm{d}}^{*}$.

\section{Conclusions}

This paper verifies that constant flow cannot be attained by arbitrary collocations of design parameters. The design requirements for constant flow must satisfy that dimensionless displacement coefficient $(d d c)$ of spool minus one can be equal to the 

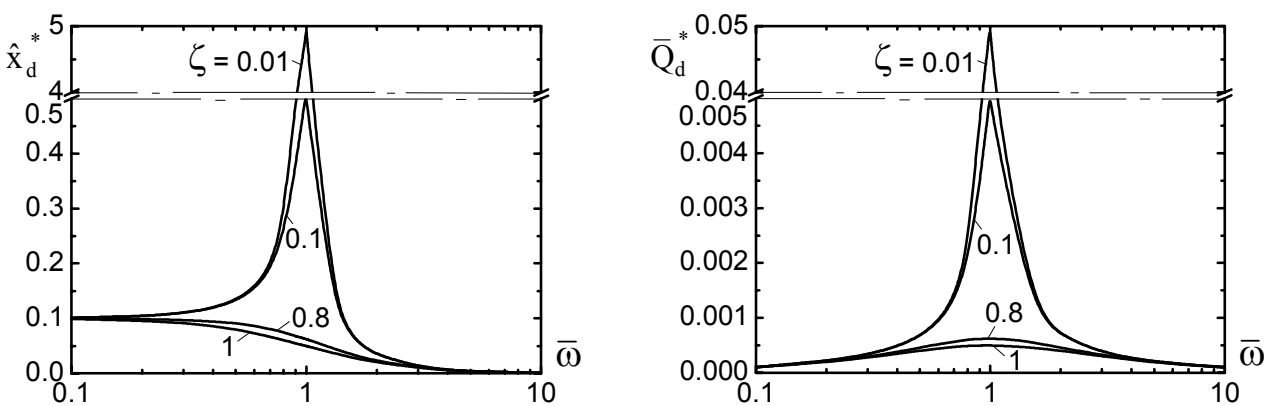

(a) $\overline{\mathrm{P}}_{\mathrm{rs}}=0.5$
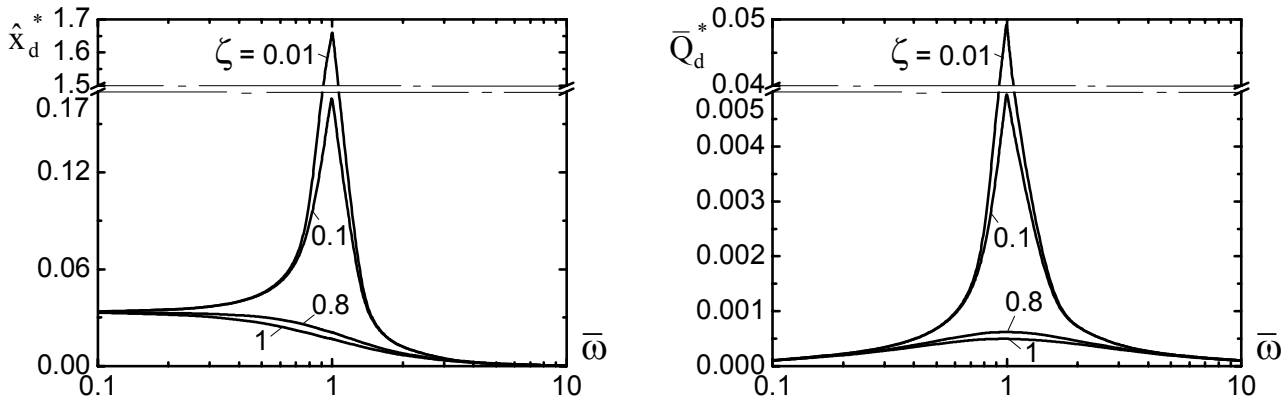

(b) $\overline{\mathrm{P}}_{\mathrm{rs}}=0.7$
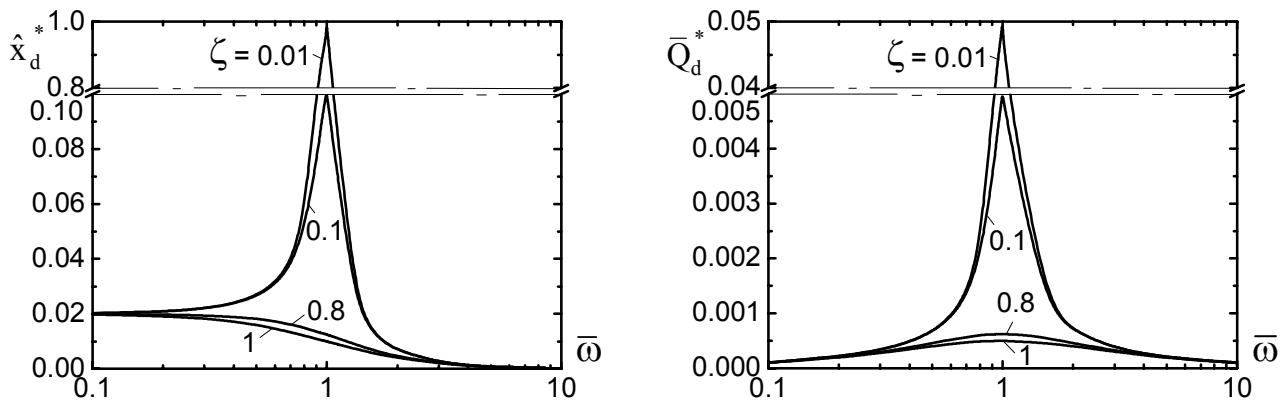

(c) $\overline{\mathrm{P}}_{\mathrm{rs}}=0.9$

Fig. 13 Amplitudes of $\hat{\mathrm{x}}_{\mathrm{d}}$ and $\overline{\mathrm{Q}}_{\mathrm{d}}$ for case $5\left(\overline{\mathrm{Q}}_{\mathrm{S}}=0.6\right)$ as $\overline{\mathrm{P}}_{\mathrm{rd}}^{*}=0.01$

product of $d d c$ and equivalent pressure ratio of spring preload. Constant dimensionless flow rate is equal to inverse $d d c$ and constant flow rate is proportional to cubic clearance and spring constant, but inversely to viscosity of oil and spool diameter. The results of dynamic analysis reveal that the amplitude of spool displacement is suppressed by static pressure ratio but proportional to the amplitude of dynamic pressure ratio. The amplitude of flow rate cannot be influenced by static pressure ratio but can be influenced by damping ratio, excitation frequency and proportional to the amplitude of dynamic pressure ratio.

\section{Acknowledgement}

The authors greatly appreciate for the support of this work by National Science Council (NSC) via the fund NSC92-2212-E-033-016.

\section{References}

(1) Rippel, H. C., Cast Bronze Hydrostatic Bearing Design Manual, (1964), Cast Bronze Bearing Institute, Inc., Cleveland, Ohio.

(2) Bassani, R., Piccigallo, B., Hydrostatic Lubrication, (1992), Elsevier Science Publishers, Amsterdam. 
(3) Rowe, W.B., Hydrostatic, Aerostatic and Hybrid Bearing Design, (2012), pp. 83-113, Butterworth-Heinemann, London.

(4) Bassani, R., Hydrostatic systems supplied through flow dividers, Industrial Lubrication and Tribology, Vol. 34 (2001), pp. 25-38.

(5) Kang, Y., Chen, C.-H., Lee, H.-H., Hung, Y.-H., Hsiao, S.-T., Design for static stiffness of hydrostatic bearings: single-action variable compensations, Industrial Lubrication and Tribology, Vol. 63, No. 2, pp.103-118.

(6) Kang, Y., Peng, D. X., Lee, H. H., Hu, S. Y., Chang, Y. P., Investigations of constant-flow valves for hydrostatic bearings, (will be published in issue 6, 2013 of) Industrial Lubrication and Tribology.

(7) Kang, Y., Hu, S. Y., Chou, H. C., Lee, H. H., Dynamic characteristics of the DSI-type constant-flow valves, Journal of Advanced Mechanical Design, Systems, and Manufacturing, Vol. 6, No. 4 (2012), pp. 456-463. 